\title{
The Failure of Failure: Postdigital Aesthetics Against Techno-mystification
}

\author{
Kim Cascone ${ }^{1} \cdot$ Petar Jandrić $^{2}$ \\ Accepted: 23 November 2020 / Published online: 17 January 2021 \\ (C) The Author(s), under exclusive licence to Springer Nature Switzerland AG part of Springer Nature 2021
}

Keywords Postdigital · Computermusic · Art · Glitch · Aesthetics · Avant-garde · Deepfake - Kim Cascone

Kim Cascone received his formal training in electronic music at the Berklee College of Music in the early 1970s and in 1976 continued his studies with Dana McCurdy at the New School in New York City. After moving to San Francisco in the 1980s and gaining experience as an electronic technician in the audio industry, Cascone worked with David Lynch as assistant music editor on 'Twin Peaks' and 'Wild at Heart'. Cascone left the film industry in 1991 to concentrate on his company Silent Records, a label that he founded in 1986, transforming it into the US's premier ambient electronic music label. In early 1996, he sold the company to pursue a career as a sound designer for Thomas Dolby's company Headspace. Two years later, he moved to Staccato Systems, where he oversaw sound design using algorithmic synthesis for video games.

From 2001 until 2015, Cascone toured Europe performing, conducting workshops, and lecturing on postdigital aesthetics in sound art. In 2015 Cascone ceased performing and lecturing in Europe and resurrected his record label Silent Records. Cascone also founded and curates a film festival whose focus is the representation of sonic drones in cinematic form called Drone Cinema Film Festival. Cascone still releases music on Silent with his new modal-drone guitar-based project Khem One.

Cascone has released more than 50 albums of electronic music since 1984 and has recorded/performed with Merzbow, Keith Rowe, Tony Conrad, Scanner, John Tilbury, and Pauline Oliveros among others. Cascone is the founder of the .microsound list

Kim Cascone

kim@ silentrecords.us

Petar Jandrić

pjandric@tvz.hr

1 Silent Records, Pacifica, California 94044, USA

2 Zagreb University of Applied Sciences, Croatia, and University of Wolverhampton, Wolverhampton, UK 
which focuses on postdigital music and laptop performance, and his writing has been published in Computer Music Journal, Parachute, Artbyte, Soundcultures, Junk Jet, and Geometer. He guest edited and wrote for Contemporary Music Review and acts as an advisor to Interference.

In 2000 Cascone published a hugely influential article 'The aesthetics of failure: "post-digital" tendencies in contemporary computer music' (Cascone 2000a). This article has introduced the concept of the postdigital, which has soon spread across various fields including visual arts, literature, architecture, design, cultural studies, and education. Founded in 2018, Postdigital Science and Education journal and book series have started a systematic exploration of the postdigital condition in humanities and social sciences. After more years of working in the field, it is a great pleasure and a privilege to publish this interview with Kim Cascone in Postdigital Science and Education.

\section{About the Conversation}

Since the inception of Postdigital Science and Education, the community has taken the history of the concept very seriously (see Cormier et al. 2019). In October 2020, after two years of journal's publication, Petar Jandrić emailed Kim Cascone with an idea to examine his pioneering contributions to postdigital theory in the light of latest developments. Kim wanted to converse in writing, so the conversation was conducted through numerous email exchanges through October and November 2020.

\section{The Early Days}

Petar Jandrić (PJ): It is generally understood that the concept of the postdigital was first mentioned in your article "The Aesthetics of Failure: "post-digital" tendencies in contemporary computer music' (Cascone 2000a). How did you come up with the concept?

Kim Cascone (KC): Well, to be honest, the term postdigital had been in use prior to my essay 'The Aesthetics of Failure' (Cascone 2000a). In 2001 I performed at a conference on Deleuzian philosophy at the Tate in London. While visiting the gift shop a book caught my eye titled The Postdigital Membrane: Imagination, Technology and Desire by Pepperell and Punt (2000). This book was published in 2000, around the same time as my article in Computer Music Journal, but I did not know of it until I stumbled across it in the Tate bookshop. It was immediate validation that there was a concept of postdigital floating around the ether and others were developing it as a strategy of deconstruction and critique of the digital world we were wading into.

PJ: I tried to date your article and Pepperell and Punt's book and could not identify which one was published first. But time difference between your publications is not more than few months, and publication dates often depend on production issues beyond authors' influence. I think it is fair to say that you explored the concept at the same time, independently of each other, thus reflecting a certain Zeitgeist of the turn of the millennium. What happened between then and now? How did your work develop during past 20 years? 
KC: That world, being much simpler then, allowed artists and thinkers to frame and examine digital technology in ways that yielded interesting artifacts. In contrast, today's technology is so pervasive and infinitely complex I do not think a postdigital critique is possible in the digital arts. Most of the stylistic flourishes and ornaments used in popular music, and to a great extent in experimental music, foreground a digital origin or processing. Samples, glitching, auto-tune, harmonizers, all leave their tell-tale trace in today's music and become a signifier of studio wizardry, a plastic artificiality. I've said before and still believe: 'the medium is no longer the message, the tool has become the message' (Cascone 2000a).

In my own artistic practice, I've abandoned the digital as a means of creation and have gone back to simpler technologies of magnets, vacuum tubes and the electric guitar. The only critique possible now, if one could call it that, is a 'backgrounding' of digital technology, i.e. not making it the focus of an artistic work. Like Negroponte (1998) said: 'the digital revolution is over' - what we are facing now is a horse of a very different color.

PJ: And this horse offers opportunities for different styles of riding! In a 2001 interview with Jeremy Turner you said:

My view is that the laptop acts as a direct connection to the mind of a composer and bypasses most of the apparatus that has been put into place by pop culture over the past 100 years. Hence, many ideas can now be expressed which previously couldn't be because of the highly developed motor skills required to play a musical instrument... (Turner and Cascone 2001)

What are the main differences between composition and live performance on traditional instruments such as piano or guitar and on a laptop? How do they reflect on produced music?

KC: I thought about these differences a lot when I moved back to a traditional instrument (see Cascone 2010). A major difference for me was the 'point-of-origin' of musical sound. In laptop music the point-of-origin was the circuitry and code working in tandem to generate musical sound. With traditional instruments the point-of-origin was bone, flesh, breath, and physical vibration working in tandem. Roland Barthes (1978) called this ephemeral quality the 'grain'.

The digital point-of-origin takes place on an 'infinitesimal' level (electrons) where human interaction takes place through many layers of abstraction, predetermined by machine time. Whereas with a traditional instrument the point-of-origin occurs on a 'metaphysical' level, open to a host of physical and psychic conditions (grain) that determine the musical sound outside of time, experienced as a 'flow state'. I think this difference is why inventors have been unsuccessful at developing a digital controller that allows a similar complexity of expression as a traditional instrument.

PJ: And what do you mean by a 'backgrounding' of digital technology? Something along the lines of Negroponte's (1998) article 'Beyond Digital' (invisibility through ubiquity), or a more general shift of focus from technology to human beings?

KC: By backgrounding I mean deselecting focus on a particular actor/agent embedded in a larger work. I'm not sure that backgrounding alone offers an effective critique, but it does clear the canvas allowing an artist to consider other strategies. Backgrounding digital technology might be more of a personal statement a than public 
statement for the artist, but stepping away from machine time is felt by a listener. The 'grain' needs to be brought back into art and the creative process. I'll go further and say the spiritual needs to be brought back into art.

PJ: As of recently, we are witnessing an increasing interest into spiritual matters in Postdigital Science and Education community; people are writing about thing like networked religion (McLaren 2020) and mediation of transcendence, where physical bodies are extended into the cloud (Trozzo 2020). What do you mean by spiritual in this context?

KC: By spiritual I mean metaphysical, or perceiving and engaging with the material world though developing suprasensory organs of perception. Johann Wolfgang von Goethe (1995: 39) wrote: 'The human being knows himself only insofar as he knows the world; he perceives the world only in himself, and himself only in the world. Every new object clearly seen opens up a new organ of perception in us.' This focus came about through reading Rudolph Steiner (2005) on music, imagination, and spirituality.

PJ: You 'have had the privilege of growing up alongside the evolution of electronic music' (Cascone 2000b), and the history of computer music has remained your permanent fascination.

Although many composers working in the field of computer music probably do not share my interest in recycling early computer synthesized sounds, there is an emergent school of composers who are concerned with similar aesthetic issues. ... This is an important movement that combines academically developed synthesis techniques, street culture usage and a deconstructionist aesthetic. (Cascone 2000b)

What inspires your interest in past sounds; what does this interest contribute to the present and future of (your) music?

KC: Knowing the history of an artform affords perspective and a foundation from which to work. The musical literacy gained shows up in a work as depth and dimensionality. I do a lot of research prior to starting work on a piece, i.e. precomposition, because I need a vague map in order to get my bearings, to know how a medium and its tools came to be, so I can go deeper in my work. Knowing history frees one from unwittingly repeating it ad nauseam.

\section{Techno-Mystification Against Critique}

PJ: Your interest in 'edge-boundaries' of software and glitch in music is the key to understanding the concept of the postdigital (Jandrić et al. 2018). What inspired you to take your work in that direction?

KC: Edge-boundaries and glitch were ideas I formed while working at digital audio start-ups in late 1990's Silicon Valley. The software I worked with was usually in a very alpha state so everyone who used the tool acted as beta-testers. We would often work with very buggy builds that would act in unexpected ways. Failure quickly evolved from one rooted in systemic malfunction to it being a lack of intersection between intention and expectation. 
PJ: Only five years after writing 'The Aesthetics of Failure: "post-digital" tendencies in contemporary computer music' (Cascone 2000a), in an interview with Ben Nevile you said: 'I'm no longer as focussed on the idea of failure/mistakes as I used to be but I now contextualize it within the framework of information of how a system can be prone to failure.' (Cascone in Nevile 2005) Please say more about this systems approach to failure.

KC: That interview occurred around the time I began to see that the concept of 'software failure' was limited in scope. I saw how fractal-like failure could be, how it played out on various levels simultaneously, how failure could be, and was, much larger than just bugs causing malfunctions in software. And ironically, failure itself failed when corporate media appropriated its stylistic visual and sonic signifiers (glitch) from the underground causing software developers to build these effects into applications as presets for ease of use. Once the edge-boundaries of audio software were fortified a critique of digital culture became difficult - glitch and failure became fashionable plugin effects and presets signifying technological mystification or dystopian edginess. As this style gained in popularity glitch and failure briefly enjoyed being the topic $d u$ jour of academic syllabuses but eventually corporate media and the Internet exhausted it as a signifier.

PJ: Again, capitalism has managed to appropriate its own critique and turn it into another commodity. What do you mean by technological mystification in this context?

KC: Digital capitalism has gotten very efficient at quickly appropriating critiques not only of itself but also of any transgressive subject matter tossed at its machine learning inputs. And, to add fuel to flame, predictive algorithms now detect these behavioral shifts before they occur in the real world.

Techno-mystification has always been a part of electronic music. It appeared in David Tudor's tabletop of DIY electronic boxes, Tangerine Dream's wall of Moog synthesizers, in the austere theater of laptop music performances, and in the current electronic music performers rig of colored button grid-controllers and Eurorack synth modules. But in all cases, the underlying electronic circuits, algorithms/computer code remains hidden from the audience. This separation of the effect (sound) from their underlying causes (computational math) causes mystification.

PJ: But the audiences actively seek demystification! You wrote about the 'gestural theater', or the idea that audiences expect music carrying a visual counterpart.

I find it odd that people don't demand the same proof of causality from a piece of visual art but some of this has to do with the difference between temporal and spatial arts. We demand to see proof of causality when a piece is being performed realtime. We need proof that the work is not just a temporal displacement; i.e. playback of a stored 'performance'. (Turner and Cascone 2001)

What does this say about the human relationship to technology in more general?

KC: There was an early public rejection of laptop music performances due to this lack of visible causality. In fact, the public often felt cheated by laptop music performances because they believed laptop music could be performed by anyone with a laptop. A common joke was that the performer was merely checking email after pushing play on their laptop. So I'm not sure that, as a rule, audiences actively sought mystification as regards laptop music. 
That being said, there is a sweet spot of how much mystification is acceptable. There needs to be enough to create an aura of spectacle yet display human cause and effect (physical motions such as rhythmic head-bobbing, dramatic button pushing, etc.). When blinking button grid controllers and Eurorack synthesizers eventually appeared on stage (backgrounding laptops) the combination of technical and physical visual cues dialed in an acceptable sweet spot of mystification for the audience. Mystification carries with it the expectation of being entranced by spectacle.

PJ: How does the concept of the postdigital help us think about the relationship between human beings and technologies?

KC: Unfortunately, the ship of affective cultural discourse has sailed. The fact that almost every tool we use today extracts behavioral data and beams that to a corporate mothership makes us all unwitting 'data-pumps' for machine learning and facilitates the takeover of our lives by algorithms and artificial intelligence. To quote Albert Einstein, '[w]e cannot solve our problems with the same thinking we used when we created them'.

PJ: Here you are talking about communicative / data / algorithmic / surveillance / bioinformational capitalism... But we are also affected on a very personal level, for instance with radical reduction of our attention spans. What happens to ways people perceive (your) music? Have your audiences changed during the past 20 years, and if they did, now do you respond to these changes?

KC: I'm not sure how my work is received really. There are cultural expectations in any artistic genre that reward adherence to a fitness function or a trend. For example, genre categories like 'ambient' or 'drone' alert the listener to what can be expected from the music, but as an artist I do not pay attention to market expectations - though as a label boss I have to. Trends are interesting to note but not worth following most of the time. My view is that if you are feeding market expectations then you are in the business of making money, if you subvert market expectations you are in the business of making art.

PJ: This dichotomy between being an artist and a label boss fascinates me. Being an influential writer, you can probably add at least one more role to this list... How do you manage all these different roles and tensions between them? On the bright side, how do they inform each other?

KC: I think it's important that an artist learns how to build a constellation of psychic nodes that exchange energy in a network. I've worked for years to grow and nourish this inner constellation. I think this process of internal world-building, or constellationbuilding, is necessary before one can world-build externally. I resonate with music that builds a world that does not signal how it was made to the listener. This quote by Gene Youngblood (1970), 'the meta-designer creates context, not content', has been my modus operandi for decades.

PJ: And this modus operandi is beautifully seen in your aforementioned quote: '[t]he medium is no longer the message, the tool has become the message' (Cascone 2000a). This statement is so important, that we might unpack it a bit further. What, for you, is the difference between a medium and a tool? For instance, is Spotify a tool or a medium?

KC: When I made that statement, I was mainly referring to tools of digital audio becoming the message. To wit: I was invited to the studio of an ambient record label where the owner was mastering a new release. He fires up a rack-mount Lexicon reverb to sweeten the material, puts me in front of the high-end studio monitors and makes me 
listen. After a while he turns to me and whispers 'that's what money sounds like'. That experience was a eureka moment for me, it showed me how 'tools can become the message'.

This expensive-sounding reverb became the 'message' of his label; by adding this reverberant shellac to their releases the label imparted value to their CD's, it became a signifier for content that 'sounded like money' and became an expectation (of value) for their fans/consumers.

As for Spotify, it functions both a tool and a medium. It's a tool for Spotify, used to gather data from its users, and a medium for the subscribers.

PJ: In today's academic publishing we are witnessing a growing Open Access movement. In a nutshell, the argument is that knowledge is a common good that everyone should be free to access, while the cost of production should be covered in ways radically different from today's. It is easy to draw a parallel with music. One could claim, that all music is humanity's collective cultural heritage that should be free - and that we should seek for alternative and radically different ways of funding musicians. What is your take on Open Access in music? To paraphrase Stewart Brand (in Wagner 2003), does music want to be free?

KC: Our AI machine learning overlords are making this a moot question. What we are facing now is a not-so-distant future in which content will be algorithmically generated and follow a monthly-subscription-to-playlists model.

The cost of AI content will be driven to zero, subscribers will provide popularity weighting and behavioral data via playlist statistics, and tech companies will continue to make a lot of money. The general public will not really care, or be able to tell, if their earbuds are filled with music created via AI or flesh and blood artists so long as their playlists create the mood they desire.

Parallel cultural structures will continue to exist but as hobbies for the creative class since any remuneration for their labor will be uncertain. This is not a future I wish to embrace but it is the one I see on the horizon.

\section{Towards a New Postdigital Avant-Garde}

PJ: Since we started Postdigital Science and Education, a surprisingly large number of authors has focused to the 'work' done by the prefix 'post' (e.g. Sinclair and Hayes 2019). How does postdigital relate to the other posts that we know: postmodernism, postindustrial, postpunk, postcolonialism, posthumanism, and others?

KC: I have not connected the dots between the post-genres, but I think creatives tend to project possible futures for their pet disciplines when they are in a state of cultural anxiety.

PJ: Covid-19 is definitely a major cause of cultural anxiety... not the least because performing artists are now out of work due to lockdowns and restrictions. How do you see the future of your work (music composition, festival organization)? Will there ever be a return to the 'old normal'; alternatively, what might a 'new normal' look like?

KC: Yes Covid-19 has definitely ratcheted up artistic anxiety, but putting that aside for a moment, every artistic discipline has a collective energy and when that begins to stagnate artists get anxious and will either seek out new territories or project a possible future (territory) as a 'post' version of itself. 
One possible future for postdigital art I see is the use of deepfake to create work. Recently deepfake content made its appearance in a short film by South Park creators Matt Stone and Trey Parker ${ }^{1}$ and has probably inspired a legion of other well-monied production companies to jump on the bandwagon. I think deepfake tools are the next digital trend and I'm eager to see if any artists do something interesting with them.

PJ: Postdigital Science and Education has recently published a whole issue on posttruth and fake news, ${ }^{2}$ so speaking of deepfake technology, I just cannot help but ask: What happens to arts in our post-truth condition?

KC: Most deepfake is used to create content that is aimed outwards, meaning used to form a critique of events or people in the real world. I have yet to see it turned back on itself, forming a critique of itself. Inevitably, the tools used to create deepfake content become the message. The tacit joke of deepfake always reveals its punchline beforehand. This is the problem with digital art today: spectacle has more value than critical thinking.

PJ: Soon after its publication, 'The Aesthetics of Failure: "post-digital" tendencies in contemporary computer music' (Cascone 2000a) has gained a lot of attention in artistic circles. Around 2010 the concept of the postdigital has slowly entered education (see Cormier et al. 2019), and in 2018, Postdigital Science and Education was founded to systematically explore the postdigital condition in the context of humanities and social sciences (Jandrić et al. 2018). How do you feel about applications of your ideas in fields so far away from their initial context? Which postdigital lessons from the arts can be generalized into humanities and social sciences?

KC: The ideas I put forth in 'Aesthetics of Failure' (Cascone 2000a) seem quaint today. In 2020 we find ourselves teleported into an era of machine learning, artificial intelligence, internet of things, 5G, Zoom meetings, self-driving cars, deepfake media, etc. with very little critical thinking applied beforehand - so I'm not confident that technological subversion is still a relevant strategy today. I do not see any renegade artists exploring edge-boundaries or offering subversive critiques of our algorithmically generated world. Any critique or subversion that is not subsumed and de-toothed is then buried in the amnesia of media news cycles and social media. Sadly, many digital artists working today seem to worship at the feet of our technocratic overlords.

PJ: And these artists are definitely not today's avant-garde. You recently wrote: 'For a real avant-garde to exist - again - we need to reestablish a "long-view" perspective, recover from our collective amnesia, and locate ourselves in the larger historical landscape.' (Cascone 2014) What can today's artists do to escape the amnesia of media news cycles and social media? Found own label (as you did in 1984 with Silent Records) or festival (as you did in 2015 with Drone Cinema Film Festival); do something else? What would you advise to a young wannabe avant-garde artist working in 2020?

KC: My advice would be to lessen one's dependence on digital tools. I always suggest reading and doing research before starting work on an artistic project. Like Werner Herzog says: 'Read, read, read, read, read, read, read, read, read, read, read, read, read...if you do not read, you will never be a filmmaker.' ${ }^{3}$ So be a voracious

\footnotetext{
${ }^{1}$ See https://youtu.be/9WfZuNceFDM. Accessed 10 November 2020.

${ }^{2}$ See https://link.springer.com/journal/42438/volumes-and-issues/2-1. Accessed 10 November 2020.

${ }^{3}$ See https://youtu.be/RNAcQO2ZQBA. Accessed 10 November 2020.
} 
reader and keep a physical notebook of ideas and projects. By relying less on digital tools, you will gain a valuable perspective on the context of your work.

\section{References}

Barthes, R. (1978). Image-music-text. New York: Hill and Wang.

Cascone, K. (2000a). The aesthetics of failure: 'Post-digital' tendencies in contemporary computer music. Computer Music Journal, 24(4), 12-18.

Cascone, K. (2000b). Recontextualizing ambient music in Csound. In R. Boulanger (Ed.), The Csound book: Perspectives in software synthesis, sound design, signal processing, and programming. Cambridge, MA: MIT Press.

Cascone, K. (2010). Grain, sequence, system: Three levels of reception in the performance of laptop music. Contemporary Music Review, 22(4), 101-104. https://doi.org/10.1080/0749446032000156900.

Cascone, K. (2014). The Avant-Garde As Aeromancy. https://www.paradoxethereal-magazine.com/kimcascone-aeromancy/. Accessed 29 Oct 2020.

Cormier, D., Jandrić, P., Childs, M., Hall, R., White, D., Phipps, L., Truelove, I., Hayes, S., \& Fawns, T. (2019). Ten years of the postdigital in the 52group: Reflections and developments 2009-2019. Postdigital Science and Education, 1(2), 475-506. https://doi.org/10.1007/s42438-019-00049-8.

Goethe, J. W. (1995). Scientific studies. Trans. D. Miller Princeton. NJ: Princeton Universitys Press.

Jandrić, P., Knox, J., Besley, T., Ryberg, T., Suoranta, J., \& Hayes, S. (2018). Postdigital science and education. Educational Philosophy and Theory, 50(10), 893-899. https://doi.org/10.1080/00131857. 2018.1454000.

McLaren, P. (2020). Networked religion: Metaphysical redemption or eternal regret? Postdigital Science and Education. https://oi.org/10.1007/s42438-020-00112-9.

Negroponte, N. (1998). Beyond digital. Wired, 12 January. http://www.wired.com/wired/archive/6.12/ negroponte.html. Accessed 10 Nov 2020.

Nevile, B. (2005). An Interview With Kim Cascone. https://cycling74.com/articles/an-interview-with-kimcascone. Accessed 22 October 2020.

Pepperell, R., \& Punt, M. (2000). The postdigital membrane: Imagination, technology and desire. Bristol: Intellect.

Sinclair, C., \& Hayes, S. (2019). Between the post and the com-post: Examining the postdigital "work" of a prefix. Postdigital Science and Education, 1(1), 119-131. https://doi.org/10.1007/s42438-018-0017-4.

Steiner, R. (2005). The inner nature of music and the experience of tone: Selected lectures from the work of Rudolf Steiner. Trans. M. St. Goar, Ed. A. Wulsin. https:/wn.rsarchive.org/Lectures/GA283/English/ AP1983/InNaMu_index.html. Accessed 21 November 2020.

Trozzo, E. (2020). Postdigital mediation of transcendence. Postdigital Science and Education. https://doi.org/ $10.1007 / \mathrm{s} 42438-020-00135-2$.

Turner, J., \& Cascone, K. (2001). The microsound scene: An interview with Kim Cascone. CTHEORY. https://journals.uvic.ca/index.php/ctheory/article/view/14586. Accessed 10 November 2020.

Wagner, R. P. (2003). Information wants to be free: Intellectual property and the mythologies of control. Columbia Law Review, 103, 03-22. https://doi.org/10.2139/ssrn.419560.

Youngblood, G. (1970). Expanded cinema. New York: P. Dutton \& Co.. 